\title{
POLAROGRAPHIC REDUCTION OF URANIUM(VI) UNDER COMPLEXING AND NONCOMPLEXING CONDITIONS NATURE OF THE URANIUM(V) SULPHATE COMPLEX
}

\author{
Philip J. Elving and Alan F. Krivis \\ University of Michigan, Ann Arbor, Michigan
}

(Received 26 January 1959)

\begin{abstract}
The polarographic reduction of $U(V I)$ to $U(V)$ in acid solution is sensitive to both type and concentration of anion present. Consequently, the reduction was studied using perchlorate as a non-complexing anion and sulphate as a complexing anion.

In $\mathrm{HClO}_{4}$ solution, increasing the perchlorate concentration shifts $E_{\frac{1}{2}}$ to more positive potentials, which seem to correspond to junction potential effects. Increasing either $\mathrm{HClO}_{4}$ or perchlorate concentrations increases the limiting current slightly, which can be attributed to a higher rate of disproportionation of U(V); other factors, e.g., viscosity of the solution, tend to counteract the effect of the disproportionation.

In sulphate media, $\mathrm{UO}_{2}{ }^{+}$is not strongly complexed, the association constant for the U(V)sulphate complex being ca. $0 \cdot 13$, if $\mathrm{UO}_{2} \mathrm{SO}_{4}$ is the most stable uranyl sulphate complex present. The effect of acid on the stability of the latter complex confirmed its existence as an uncharged species. Limiting currents are pseudo diffusion-controlled, e.g., increasing the solution viscosity by increasing the electrolyte content decreases the current; this is due to the maximum disproportionation rate of $U(V)$ having been reached at even the lowest sulphuric acid level investigated; increasing the anion concentration consequently slows down diffusion.
\end{abstract}

THE polarographic behaviour of uranium and of its complexes, particularly those of the higher oxidation states of uranium, have been extensively examined. Study of the uranium sulphate complexes has been limited to solutions containing high concentrations of both uranium and gelatin. Consequently, the polarographic behaviour of uranyl ion at low concentration, in the absence of maximum suppressor, was investigated in complexing sulphate media and, for comparison, in noncomplexing perchlorate media.

The U(VI)-U(V) wave appears over the whole acidity range investigated (ca. $0 \cdot 2$ to $4 \mathrm{M} \mathrm{H}^{+}$); due to presence of the hydrogen ion discharge wave, reduction waves for U(V) and (IV) are observed only in solutions of low acidity. These waves are illdefined and, in sulphate media, tend to merge with the hydrogen discharge. Therefore, analysis of the data will be limited to the U(VI)-U(V) wave; this will permit comparison of the effects over the whole range of anion and acid concentrations.

Spectrophotometric studies ${ }^{(1,2)}$ have not been able to detect any perchlorate complex of U(VI), whereas at least one sulphate complex has been identified;(1) the latter has also been identified by extraction studies. ${ }^{(3)}$ These findings are supported by the radical difference in the polarographic results obtained in the present study, which indicate the distinctly different nature of the processes occurring in sulphate and in

(1) R. H. Betts and R. K. Michels, J. Chem. Soc. Supplementary issue No. 2, 5286 (1949).

(2) S. AHrLAND, Acta Chem. Scand. 3, 374 (1949); 5, 1151 (1951).

(3) K. A. Allen, J. Amer. Chem. Soc. 80, 4133 (1958). 
perchlorate media. Consequently, the discussion will be divided into two major sections, describing separately the trends in each medium.

An important factor in the polarography of uranium ${ }^{(4,5)}$ is the disproportionation of $\mathrm{U}(\mathrm{V})$ :

$$
2 \mathrm{UO}_{2}^{+}+4 \mathrm{H}^{+} \rightarrow \mathrm{UO}_{2}^{2+}+\mathrm{U}^{4+}+2 \mathrm{H}_{2} \mathrm{O}
$$

or

$$
2 \mathrm{UO}_{2}^{+}+2 \mathrm{H}^{+} \rightarrow \mathrm{UO}_{2}^{2+}+\mathrm{UO}^{2+}+\mathrm{H}_{2} \mathrm{O}
$$

The rate of this process influences the current of the first uranium wave, U(VI) $\rightarrow U(V)$, which varies between the values expected for $1 e$ and $2 e$ processes. Increasing acid concentration tends to favour the process. The optimum stability of $\mathrm{UO}_{2}{ }^{+}$is in the region of $\mathrm{pH} 2-4 .{ }^{(6)}$

In perchlorate media (ionic strength, $\mu,=0.4 \mathrm{M} ; \mathrm{UO}_{2}{ }^{+}$concentration $=10^{-3}$ $10^{-5} \mathrm{M}$ ) the rate law for the disproportionation is

$$
-d\left[\mathrm{UO}_{2}^{+}\right] / d t=k\left[\mathrm{H}^{+}\right]\left[\mathrm{UO}_{2}^{+}\right]^{2}
$$

with $k$ being $130=41$. moles $^{-1} \sec ^{-1}$ at $25^{\circ} .^{(7)}$ Below $0.5 \mathrm{M}$ acid concentration, the probable mechanism is

$$
\begin{gathered}
\mathrm{UO}_{2}^{+}+\mathrm{H}^{+} \underset{\mathrm{UOOH}^{2+}}{\stackrel{\mathrm{U}}{\leftarrow}} \\
\mathrm{UO}_{2}^{+}+\mathrm{UOOH}^{2+} \stackrel{k}{\rightarrow} \mathrm{UO}_{2}^{+}+\mathrm{UOOH}^{+} \\
\mathrm{UOOH}^{+} \rightarrow \mathrm{U}(\mathrm{IV}) \text { species }
\end{gathered}
$$

An increase of $k$ with increasing ionic strength is to be expected for an activated complex such as the $\left(\mathrm{UO}_{2} \mathrm{UOOH}\right)^{3+}$ proposed. ${ }^{(7)}$ Potentiometric study ${ }^{(8)}$ of the $\mathrm{U}(\mathrm{V})$ disproportionation kinetics in sulphate media demonstrated the probable mechanis $m$ to be the same as that in perchlorate solution.

\section{EXPERIMENTAL}

Reagents. Uranyl perchlorate, prepared by repeated evaporation of uranyl nitrate with perchloric acid, was dissolved to give a $0.1338 \mathrm{M}$ solution. A $0.0640 \mathrm{M}$ uranyl sulphate solution was prepared from the C.P. grade salt (Fisher Scientific Co.). The exact uranium concentrations were determined by reduction (Jones reductor), aeration and titration (standard dichromate solution with sodium diphenylaminesulfonate as indicator).

Nitrogen used for deoxygenating solutions was purified and equilibrated by two alkaline pyrogallol scrubs and passage through a portion of the proper background electrolyte solution. All other chemicals were reagent grade and were used without further purification.

Procedure. Sufficient uranyl solution to produce the desired concentration at final dilution was added to the proper quantities of acid and salt; the solution was brought to volume and mixed; a portion was transferred to a thermostated H-cell kept at $25.0 \div 0.1 \mathrm{C}$. (Sodium sulphate was used to increase the ionic strength in the sulphate acid series and sodium perchlorate in the perchloric acid series.) The solution was deoxygenated with nitrogen for $15 \mathrm{~min}$ and polarographed with a Leeds and Northrup Type E Electro-Chemograph. $E_{1}$ and $i_{1}$ values were determined graphically, using the average of the recorder trace swings. In order to avoid precipitation of potassium perchlorate. the agar salt bridge in the $\mathrm{H}$-cell was made with sodium chloride.

(1) I. M. Kolthoff and J. J. LiNgane, Polarography (2nd Ed.). Interscience Publishers, New York (1952).

(5) P. J. ELVING and A. F. KRIVIS, Analyt. Chem. 29, 1292 (1957).

(6) K. A. Kraus, F. Nelson and G. L. Johnson, J. Amer. Chem. Soc. 71, 2510 (1949).

(7) D. M. H. KeRN and E. F. OrlemanN, J. Amer. Chem. Soc. 71, 2102 (1949).

(8) H. G. HeAL and J. G. N. Thomas, Trans. Faraday Soc. 45, 11 (1949). 
The data presented are for $0.802 \mathrm{mM} \mathrm{U}(\mathrm{VI})$ in perchlorate media and for $1.28 \mathrm{mM} \mathrm{U}(\mathrm{VI})$ in sulphate media. Data were also obtained for 0.267 and $2.67 \mathrm{mM} \mathrm{U(VI)} \mathrm{in} \mathrm{perchlorate} \mathrm{media,} \mathrm{but} \mathrm{are}$ the same as those for $0.802 \mathrm{mM}$ U(VI), i.e., $E_{\frac{1}{2}}$ is identical and $i_{1}$ is the proper fraction or multiple.

\section{Perchlorate media}

Spectrophotometrically, no complexation of $\mathrm{U}(\mathrm{VI})$ was observed on varying the $\mathrm{HClO}_{4}$ concentration from 2 to $6 \mathrm{M}$.(1)

Variation of $E_{1}$. At constant $\mathrm{HClO}_{4}$ concentration, increasing ionic strength by $\mathrm{NaClO}_{4}$ addition linearly shifts $E_{\frac{1}{2}}$ to more positive potential (Fig. 1B). Twelvefold variation of the acid concentration does not change $E_{1}$ or curve shape excessively;

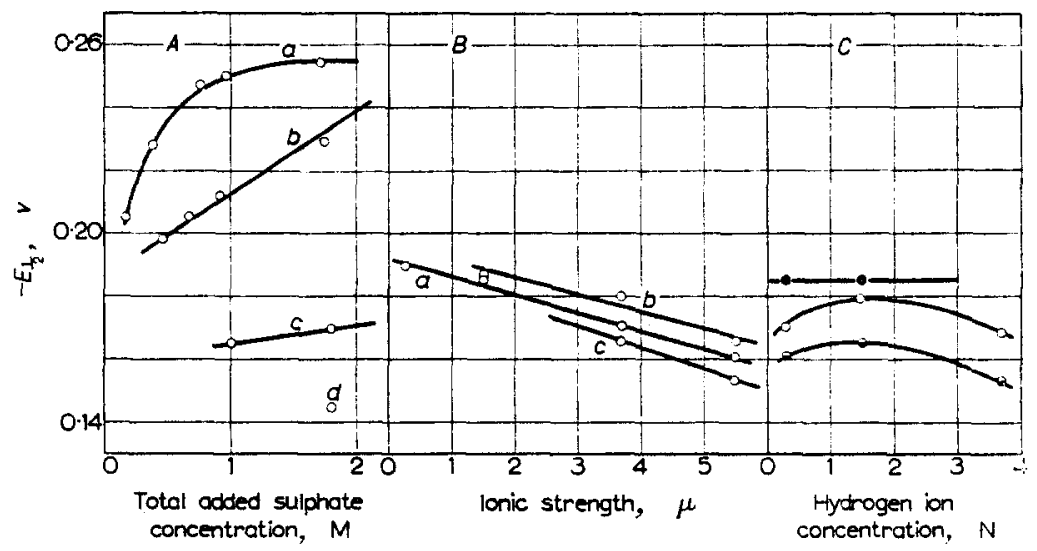

FIG. 1. Dependence of $E_{z}$ on solution composition.

(A) $E_{\frac{1}{2}}$ as a function of total gross sulphate concentration at constant sulphuric acid concentration. $\mathrm{H}_{2} \mathrm{SO}_{4}$ concentration: $a, 0.18 \mathrm{M} ; b, 0.36 \mathrm{M} ; c, 1.0 \mathrm{M} ; d, 1.8 \mathrm{M}$.

(B) $E_{\frac{1}{3}}$ as a function of ionic strength at constant perchloric acid concentration. $\mathrm{HClO}_{4}$ concentration: $a, 0.29 \mathrm{M} ; b, 1.47 \mathrm{M} ; c, 3.68 \mathrm{M}$.

(C) $E_{\frac{1}{3}}$ as a function of $\mathrm{HClO}_{4}$ concentration at constant ionic strength. Ionic strength for perchlorate solutions: $0,1.5 \mathrm{M} ; 0.3 .7 \mathrm{M} ; 0,5.5 \mathrm{M}$.

the variation in $E_{1}$ is almost within experimental error. Plots of $E_{f}$ vs. $\left[\mathrm{H}^{+}\right]$ (actually acid normality) (Fig.1C) show increasingly nonlinear response to increasing $\mu$.

Apparently, at lower ionic strength $E_{\frac{1}{2}}$ is independent of acid concentration, but at higher $\mu$ becomes sensitive to $\left[\mathrm{H}^{+}\right]$. However, since the electrode reaction, $\mathrm{U}(\mathrm{VI}) \rightarrow(\mathrm{V})$, has been shown ${ }^{(9,10)}$ to be reversible and not to involve $\mathrm{H}^{+}, E_{\mathrm{l}}$ should be independent of $\left[\mathrm{H}^{+}\right]$. Furthermore, the lowest ionic strength used (Fig. 1C) is quite high $(1.5 \mathrm{M})$ and further increase in it should not have a noticeable effect. (The activity coefficient of $\mathrm{H}^{+}$for various $\mathrm{HClO}_{4}$ concentrations is as follows: 0.77 at $\mu=0.29,0.92$ at $\mu=1.5$ and 1.8 at $\mu=3.7$. (11) Data for $\mathrm{HClO}_{4}-\mathrm{NaClO}_{4}$ solutions could not be located.)

The results are reminiscent of the similar type of curvature reported for the $E_{1}-\mu$ plot for cadium(II), which was ascribed to the effects of junction potential and complex formation. ${ }^{(12)}$ However, it is difficult to compare the latter data with the present results since $\mathrm{U}(\mathrm{VI})$ and its reduction products are soluble, whereas $\mathrm{Cd}(\mathrm{II})$ is reduced to the amalgam.

(9) W. E. Harris and I. M. Kolthoff, J. Amer. Chem. Soc. 67, 1484 (1945).

(10) E. S. Kritchevsky and J. C. Hindman, J. Amer. Chem. Soc. 71, 2096 (1949).

(11) B. E. Conway, Electrochemical Data. Elsevier, Amsterdam (1952).

(12) D. D. DeFord and D. L. ANDERSEN, J. Amer. Chem. Soc. 72, 3918 (1950). 
The Nernst equation for the reversible $U(V I)-U(V)$ reduction indicates that an increase in ionic strength through its effect on the activity coefficients of the two uranium species should shift potentials to more negative values, if at all;(4) the experimental data (Fig. 1B) shows the opposite. The linear dependence of $E_{\frac{1}{2}}$ on $\mu$ indicates a systematic factor to be operative. In $0.29 \mathrm{M} \mathrm{HClO}_{4}$, a difference of $28 \mathrm{mV}$ was found between the $E_{3}$ values obtained in the lowest and highest $\mu$ solutions; the difference in $\mathrm{pH}$ found for the same $\mathrm{HClO}_{4}-\mathrm{NaClO}_{4}$ solutions with a glass electrode corresponded to a potential difference in the same direction of $38 \mathrm{mV}$, indicating that most of the $E_{1}$ shift is likely due to junction potentials. The acid and salt concentrations



FIG. 2.-Limiting currents, $i_{1}$, as a function of the total gross anion concentration at constant acid concentration. $\mathrm{HClO}_{4}$ concentration: $a, 0.29 \mathrm{M} ; b, 1.47 \mathrm{M} ; c, 3.68 \mathrm{M} . \mathrm{H}_{2} \mathrm{SO}_{4}$ concentration: $d, 0.18 \mathrm{M} ; e, 0.36 \mathrm{M} ; f, 1.0 \mathrm{M}$.

used preclude the calculation of-or for that matter, the approximation of-the activity coefficients of the uranium species.

Current variation. Usually, with a diffusion-controlled process, increasing the ionic strength increases the viscosity of the solution which, in turn, should decrease the rate of diffusion of the electroactive species to the electrode; this would then be reflected in a lower observed $i_{1}$. At low acid concentration $i_{1}$ for the U(VI)-U(V) wave is independent of ionic strength (Fig. 2); at higher acid concentration, it increases with increasing $\mu$.

Since the $0.29 \mathrm{M}$ acid is well outside the optimum stability range of $\mathrm{U}(\mathrm{V})$ with respect to disproportionation, almost all $U(V)$ produced at the electrode should immediately disproportionate. Further addition of acid should only slightly more favour the disproportionation and the current should rise only slightly; this is the case. The increase in slope of the current-anion concentration relation can be similarly interpreted.

At relatively low ionic strength, i.e. $0.4 \mathrm{M}$, an increase in $\mu$ increases the rate constant of the $U(V)$ disproportionation ; ${ }^{(7)}$ the explanation for this was based on the premise that the activated species was sensitive to the ionic atmosphere. In all probability, the same effect causes the present observed rise in $i_{1}$. Therefore, at $0 \cdot 29 \mathrm{M}$ acid the increase in viscosity caused by the increase in $\mu$ is apparently just counteracted by the increase in disproportionation rate, and no reduction in wave height is found. 
At higher acid concentrations, the increased disproportionation rate not only neutralizes the effect of the decreased diffusion rate, but enhances the current, producing the rising slope in the current-anion concentration relation.

\section{Sulphate media}

The interpretation of the data in sulphate solution is complicated by the computation of the concentrations of the ionic species $\left(\mathrm{H}^{+}, \mathrm{HSO}_{4}^{-}\right.$and $\left.\mathrm{SO}_{4}{ }^{2-}\right)$ and consequently of the ionic strength, due to the variation of the bisulphate ion dissociation quotient,

$$
Q=\frac{\left[\mathrm{H}^{+}\right]\left[\mathrm{SO}_{4}{ }^{2-}\right]}{\left[\mathrm{HSO}_{4}^{-}\right]}
$$

with ionic strength. Calculations of the quantities indicated were made on three bases: (a) assuming a $Q$ value of 0.012 , which corresponds to infinite dilution, (b)

Table 1. Polarographic behaviour of uranium(VI) in sulphuric acid solution containing VARIABLE AMOUNTS OF SODIUM SULPHATE

\begin{tabular}{|c|c|c|c|c|c|c|c|}
\hline \multirow[b]{2}{*}{$\begin{array}{c}\mathrm{H}_{2} \mathrm{SO}_{4} \\
(\mathrm{M})\end{array}$} & \multirow[b]{2}{*}{$\begin{array}{c}\mathrm{Na}_{2} \mathrm{SO}_{4} \\
(\mathrm{M})\end{array}$} & \multicolumn{2}{|c|}{ Wave $1^{*}$} & \multirow[b]{2}{*}{$\begin{array}{c}\mathrm{H}_{2} \mathrm{SO}_{4} \\
(\mathrm{M})\end{array}$} & \multirow[b]{2}{*}{$\begin{array}{c}\mathrm{Na}_{2} \mathrm{SO}_{4} \\
(\mathrm{M})\end{array}$} & \multicolumn{2}{|c|}{ Wave $1^{*}$} \\
\hline & & $\begin{array}{l}-E_{\mathrm{t}} \\
(\mathrm{V})\end{array}$ & $\begin{array}{c}i_{1} \\
(\mu \mathrm{A})\end{array}$ & & & $\begin{array}{l}-E_{1} \\
\text { (V) }\end{array}$ & $\begin{array}{c}i_{1} \\
(\mu \mathrm{A})\end{array}$ \\
\hline 0.18 & 0.00 & 0.205 & 6.7 & $0 \cdot 36$ & 0.00 & $0 \cdot 198$ & $7 \cdot 1$ \\
\hline 0.18 & .0 .20 & 0.223 & 6.9 & 0.36 & $0 \cdot 30$ & 0.205 & 6.9 \\
\hline 0.18 & 0.60 & 0.247 & $6 \cdot 3$ & $0 \cdot 36$ & 0.60 & 0.212 & 6.5 \\
\hline 0.18 & 0.80 & 0.250 & $6 \cdot 2$ & $0 \cdot 36$ & $1 \cdot 40$ & 0.229 & $5 \cdot 5$ \\
\hline 0.18 & $1 \cdot 50$ & 0.254 & $5 \cdot 2$ & & & & \\
\hline 1.00 & 0.00 & $0 \cdot 165$ & $7 \cdot 3$ & 1.8 & 0.00 & 0.145 & $7 \cdot 4$ \\
\hline & 0.80 & 0.170 & 6.5 & & & & \\
\hline
\end{tabular}

\footnotetext{
- Solution was $1.28 \mathrm{mM}$ in U(VI). The same capillary was used in all of the sulphate experiments $\left(t=4.0 \mathrm{sec}\right.$ and $m=1.9 \mathrm{mg} / \mathrm{sec}$ at open circuit). The $i_{1}$ values are given to indicate the variation with solution composition.
}

assuming a "large" value of $Q$, corresponding to nearly complete dissociation, and (c) using BAEs' estimation of bisulphate ion dissociation. ${ }^{(13)}$ Although the three approaches obviously gave differently shaped curves for plots of $E_{t_{2}}$ or $i_{1}$ vs. $\mu,\left[\mathrm{H}^{+}\right]$ or $\left[\mathrm{SO}_{4}=\right]$, the general trends within the series of each constant acid concentration were similar. Consequently, the experimental values of $E_{\xi}$ and $i_{1}$ are given in Table 1, from which trends can be realized.

At $0.18 \mathrm{M} \mathrm{H}_{2} \mathrm{SO}_{4}$, increasing the $\mathrm{Na}_{2} \mathrm{SO}_{4}$ concentration shifts $E_{1}$ exponentially to more negative potential (Fig. 1A). With increasing $\mathrm{H}_{2} \mathrm{SO}_{4}$ concentration, the curvature is eliminated and $E_{\text {子 }}$ becomes slightly but apparently linearly more negative (13) C. F. BAEs, J. Amer. Chem. Soc. 79, 5611 (1957). 
with increasing total sulphate concentration, although the slope of the plot decreases considerably.

At constant ionic strength (calculated on different bases), the plot of $E_{\frac{1}{2}}$ vs. $\left[\mathrm{H}^{+}\right]$ is apparently exponential and independent of ionic strength since two differing constant $\mu$ series gave similarly shaped curves.

At constant acid concentration $i_{1}$ decreases linearly with increasing added sulphate concentration (Fig. 2); increasing the acid concentration increases $i_{1}$ but does not change the slope of the $i_{1}$-"anion" concentration relation.

These results are consistent with those expected for complexed species.

Although HeAL ${ }^{(14)}$ concluded that $\mathrm{UO}_{2}{ }^{2+}$ and its reduction products do not form strong sulphate complexes, both his polarographic data and those of WATTERS (15) indicate that the presence of sulphate changes polarographic values considerably beyond the variations expected for experimental error; therefore complexation is likely involved. Furthermore, even at very low $\mathrm{H}_{2} \mathrm{SO}_{4}$ concentration $i_{1}$ for the first wave is more than that for a $l e$ reduction. Increasing the $\mathrm{H}_{2} \mathrm{SO}_{4}$ concentration to 0.5 to $1.0 \mathrm{M}$ increases the wave height to about that for a $2 e$ reduction. (15) Since the acid concentration is distinctly below the $6 \mathrm{M}$ level at which the wave approaches a $2 e$ height in hydrochloric acid solution, ${ }^{(9,16,17)}$ the current increase must be due to complexation. If either the $\mathrm{U}(\mathrm{VI})$ or $\mathrm{U}(\mathrm{IV})$ sulphate complexes are more stable than the $U(V)$ complex, the disproportionation (equation (1)) will be favoured and the first wave current will increase. HEAL ${ }^{(\mathbf{1 4})}$ based his conclusions on the low stability of sulphate complexes on the constancy of $E_{\frac{1}{2}}$ in both chloride and sulphate media. However, since he used a high uranium concentration $(0.01 \mathrm{M})$ and a gelatin concentration $\left(0.02\right.$ per cent) sufficient to cause anomalies, ${ }^{18,19)} E_{\frac{1}{2}}$ in the two media may be further apart than his results indicate.

Nature of the $\mathrm{U}(\mathrm{VI})$-and $\mathrm{U}(\mathrm{V})$-sulphate complexes. In a spectrophotometric study (1) of the complexation of U(VI), the species in $2 \mathrm{M} \mathrm{H}_{2} \mathrm{SO}_{4}$ seemed to have a uranium : sulphate ratio of $1: 1$ with two major possible forms: $\mathrm{UO}_{2} \mathrm{HSO}_{4}{ }^{+}$and $\mathrm{UO}_{2} \mathrm{SO}_{4}$. The equilibria involved,

$$
\begin{gathered}
\mathrm{UO}_{2}{ }^{2+}+\mathrm{HSO}_{4}^{-} \rightleftarrows \mathrm{UO}_{2} \mathrm{HSO}_{4}^{+} \\
\mathrm{UO}_{2}{ }^{2+}+\mathrm{HSO}_{4}^{-} \rightleftarrows \mathrm{UO}_{2} \mathrm{SO}_{4}+\mathrm{H}^{+}
\end{gathered}
$$

indicate that the bisulphate complex concentration would be relatively independent of small changes in the acid concentration at the $2 \mathrm{M}$ level, whereas the concentration of the neutral sulphate species would be increased by a reduction in acid concentration. Since decreasing the acid concentration does increase the concentration of the complexed form, the most likely species is the neutral $\mathrm{UO}_{2} \mathrm{SO}_{4}$, whose association constant was determined to be $5 \cdot 0 \pm 0 \cdot 34$. $^{(1)}$

If the first uranium wave is assumed due to the reaction

$$
\mathrm{UO}_{2}\left(\mathrm{SO}_{4}\right)_{p}^{-2(p-1)}+e \rightleftarrows \mathrm{UO}_{2}\left(\mathrm{SO}_{4}\right)_{q}^{-(2 q-1)}+(p-2) \mathrm{SO}_{4}{ }^{2-}
$$

(14) H. G. Heal, Trans. Faraday Soc. 45, 1 (1949).

(15) J. I. WATTERS, U.S.A.E.C. Report CC-2771 (1945).

(16) W. E. Harris, Ph.D. Thesis, University of Minnesota (1945).

(17) I. M. Kolthoff and W. E. Harris, J. Amer. Chem. Soc. 68, 1175 (1946).

118) E. F. OrlemanN and D. M. H. Kern, J. Amer. Chem. Soc. 75, 3058 (1953),

(19) L. Meites and T. Mertes, J. Amer. Chem. Soc. 73, 177 (1951). 
the relevant equation for $E_{t}$ at $25^{\circ}$ is ${ }^{(4)}$

$$
E_{\mathrm{l}}=E^{\circ}-\frac{0.0591}{a} \log \frac{K D_{\mathrm{ox}}^{1 / 2}}{K D_{\mathrm{red}}^{1 / 2}}-(p-q) \frac{0.0591}{a} \log \text { [ligand] }
$$

If the diffusion coefficients of $U(V I)$ and $U(V)$ are assumed to be essentially equal, the slope of $E_{1}-\log$ [ligand] plots gives

$$
\frac{\Delta E_{\frac{1}{2}}}{\Delta \log [\text { ligand }]}=\frac{-0.0591}{a}(p-q)
$$

Since reduction of $\mathrm{UO}_{2}{ }^{2+}$ to $\mathrm{UO}_{2}{ }^{+}$involves one electron, and since the most stable sulphate complex at the higher $\mathrm{H}_{2} \mathrm{SO}_{4}$ concentration $(2 \mathrm{M}$ ) contains one sulphate ion, equation (11) simplifies to

$$
\frac{\Delta E_{\frac{1}{2}}}{\Delta \log [\text { ligand }]}=-0.0591(1-q)
$$

Plots of $E_{f}$ vs. $\log \left[\mathrm{SO}_{4}{ }^{2-}\right]$ can be used to evaluate $q$.

On the basis of $\left[\mathrm{SO}_{4}{ }^{2-}\right]$ calculated in various ways as mentioned, the slope $\left(\Delta E_{1} / \Delta \log \left[\mathrm{SO}_{4}=\right]\right)$ decreases as the acid concentration is increased, being -0.05 to -0.06 at $0.18 \mathrm{M} \mathrm{H}_{2} \mathrm{SO}_{4}$, ca. -0.04 at $0.36 \mathrm{M}$, and ca. -0.02 at $1.0 \mathrm{M}$. Therefore, at the lowest ionic strength and acid concentration studied, $0.18 \mathrm{M}$, the $U(V)$ species is only slightly complexed by sulphate, probably existing mostly as an aquated ion. The latter fact plus the decrease in slope with increasing acid concentration indicate that the addition of acid strips the sulphate off the uranium(VI); such behaviour supports the contention that the most probable $U(V I)$ species is the neutral complex $\left[\mathrm{UO}_{2} \mathrm{SO}_{4}\right]$.

$E_{\frac{1}{2}}$ corresponding to $\log$ [ligand] $=0.0$ is the standard reduction potential, $\left(E_{\frac{1}{2}}\right)_{c}$, of the complex ${ }^{(4)}$ and

$$
\left(E_{\frac{1}{2}}\right)_{c}-\left(E_{\frac{1}{2}}\right)_{s}=\frac{0.0591}{\mathrm{a}} \log \frac{K_{\text {o.c. }}}{K_{\text {r.c. }}}
$$

where $\left(E_{1}\right)_{s}$ is $E_{1}$ of the uncomplexed ion, $K_{o . e .}$ is the dissociation constant for the oxidized species, and $K_{\text {r.c. }}$ is that for the reduced species.

For the U(VI)-(V) wave, $a=1$ and $\left(E_{1}\right)_{s}=-0.180 \mathrm{~V} ;{ }^{(7)}$ therefore, at $0.18 \mathrm{M}$ sulphuric acid (lowest $\mathrm{H}_{2} \mathrm{SO}_{4}$ concentration used which gave maximum rate of slope for $E_{1}$ vs. $\log \left[\mathrm{SO}_{4}^{2-}\right]$ ),

$$
-(0.252 \text { to } 0.257)-(-0.180)=0.0591 \log \frac{K_{\text {o.e. }}}{K_{\text {r.c. }}}
$$

The ratio of $K_{\text {o.c. }}$ to $K_{\text {r.c. }}$ is then 0.05 to 0.06 . Since $K_{\text {o.c. }}$ has been found to be $0.4,{ }^{(1)}$ $K_{\text {r.c. }}$ is approximately 7 or 8 . The association constant for a $\mathrm{U}(\mathrm{V})$-sulphate complex would be 0.13 to 0.14 , which is in agreement with qualitative deduction as to the low stability of any $\mathrm{U}(\mathrm{V})$-sulphate complex.

The variation of $E_{1}$ with sulphate concentration (Fig. 1A) is dependent on the $\mathrm{H}_{2} \mathrm{SO}_{4}$ concentration level. At low acid concentrations, complexation is probably the major factor in the potential shifts. As the acid concentration is increased, the increasingly large junction potential seems to diminish the apparent effect of $\left[\mathrm{SO}_{4}{ }^{2-}\right.$ ] on $E_{1}$. Unfortunately, the effect of activity on the complex cannot be evaluated.

The variation of current with sulphate concentration (Fig. 2) shows a pseudo 
diffusion-controlled process instead of the catalytic current effect actually present. As the sulphate concentration is increased, the current decreases. The uranium wave in high acid and sulphate concentrations is affected by the increase in viscosity in the same manner as a diffusion-controlled reaction would be; the maximum rate of disproportionation has been reached, and consequently, further addition of sulphate can only affect the viscosity of the solution and thus decrease the current flow.

Acknowledgement--The authors wish to thank the Atomic Energy Commission, which helped support the work described. 